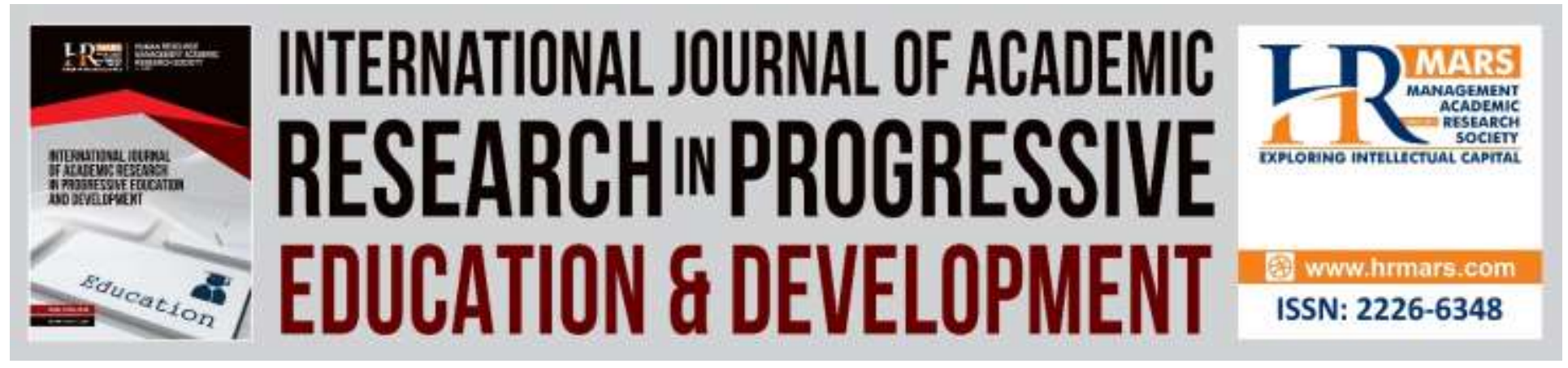

\title{
Model-View-Controller based Context Visualization Method for Multimedia English Teaching System: A Case Study of Multimedia Technology Teaching
}

Lu Juan and Noraffandy Bin Yahaya

To Link this Article: http://dx.doi.org/10.6007/IJARPED/v9-i2/7183

DOI:10.6007/IJARPED/v9-i2/7183

Received: 15 February 2020, Revised: 18 March 2020, Accepted: 11 April 2020

Published Online: 30 April 2020

In-Text Citation: (Juan \& Yahaya, 2020)

To Cite this Article: Juan, L., \& Yahaya, N. Bin. (2020). Model-View-Controller based Context Visualization Method for Multimedia English Teaching System :A Case Study of Multimedia Technology Teaching. International Journal of Academic Research in Progressive Education and Development, 9(2), 14-34

Copyright: (C) 2020 The Author(s)

Published by Human Resource Management Academic Research Society (www.hrmars.com)

This article is published under the Creative Commons Attribution (CC BY 4.0) license. Anyone may reproduce, distribute, translate and create derivative works of this article (for both commercial and non-commercial purposes), subject to full attribution to the original publication and authors. The full terms of this license may be seen

at: http://creativecommons.org/licences/by/4.0/legalcode

Vol. 9(2) 2020, Pg. 14 - 34

http://hrmars.com/index.php/pages/detail/IJARPED

JOURNAL HOMEPAGE

Full Terms \& Conditions of access and use can be found at http://hrmars.com/index.php/pages/detail/publication-ethics 


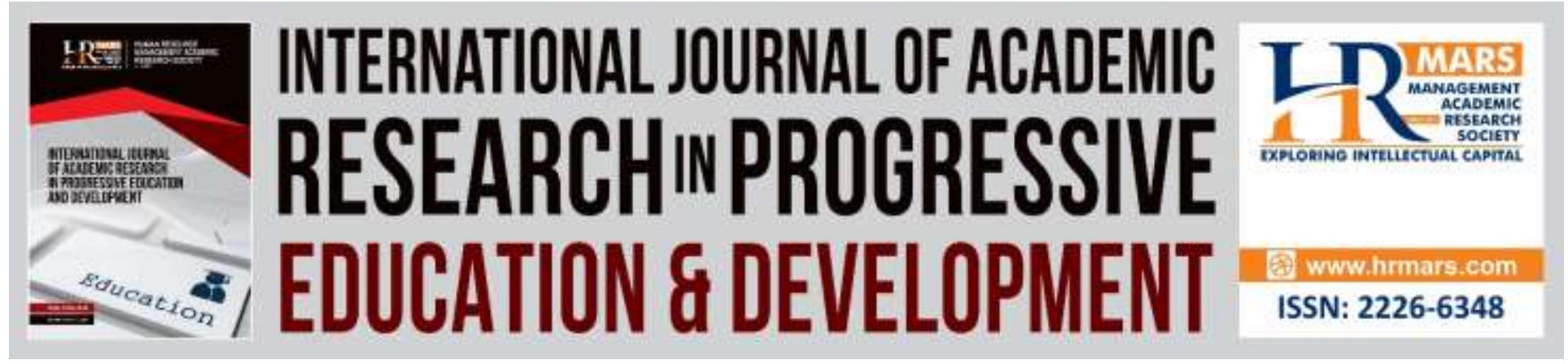

\title{
Model-View-Controller based Context Visualization Method for Multimedia English Teaching System :A Case Study of Multimedia Technology Teaching
}

\author{
Lu Juan ${ }^{1}$ and Noraffandy Bin Yahaya ${ }^{2}$ \\ ${ }^{1}$ School of Education, Universiti Teknologi Malaysia, Malaysia, School of Foreign Studies, \\ Shaanxi University of Technology, China, ${ }^{2}$ School of Education, Universiti Teknologi Malaysia, \\ Malaysia
}

\begin{abstract}
With the rapid development of multimedia technology, the medium of multimedia has become an indispensable part of in modern education. College English teaching should also be combined with multimedia technology because the traditional College English teaching has singular teaching method, limited teaching resource, poor learning efficiency and low interest of students. Therefore, this paper initiates to design a multimedia teaching system based on B/S network model and MVC design pattern for college English reading teaching. This teaching innovation is based on B/S network mode and MVC design mode, and is composed of Web service layer, client layer and database service layer. The system adopts B/S network and MVC design pattern fusion mode to realize hierarchical control, and different data classification. It refines the functional division of teaching resources, thus greatly improving the capacity of data circulation in the teaching system. The system function design includes four parts: user registration and login, teacher's teaching, student's learning and administrator's management. The teacher's teaching module completes the teacher's uploading and online answering function for college English reading materials. The student learning module enables students to obtain classroom learning content and reading resource. Finally, this research discovered that the design of this system has improved the students' interest in learning English and the teaching quality has also been significantly improved.
\end{abstract}

Keywords: Multimedia Teaching; B/S; MVC (Model-View-Controller) Design, College English Teaching.

\section{The Status Que of Multimedia Teaching}

With the continuous development of quality education, the traditional English teaching mode "teachers teach while students listen" gradually declined, replaced by pictures, video and audio, lifelike and interesting multimedia teaching (Gopalakrishnan, Rangan, Ramkumar \& 
Hariharan, 2019). Traditional teaching activities are a process of imparting knowledge to students with a variety of information, and multimedia technology is a form of technology that can provide information to students through multidimensional senses through diversified forms of information. To cultivate students' practical language communication competence, multimedia technology can provide a realistic and vivid language learning and communication environment. Based on the function of multimedia technology and the purpose of English teaching, the traditional passive college English teaching has been out of date and will be superseded by active multimedia technology.

When you walk into the university campus, it is not difficult to find that each classroom is equipped with multimedia teaching resources. All the Teachers use the PPT to produce relevant content as stipulated in the syllabus to present their teaching. Multimedia teaching is mainly the practical application of computer-based multimedia technology in the teaching process, mainly the use of computers, mobile phones and the use of premade multimedia teaching software, teaching APP, WeChat platform and other teaching activities. The flourishing development of multimedia teaching reflects the need for teaching development and is derived from long-term practice by students and teachers. In foreign countries, multimedia technology began to be introduced into the teaching of schools in the 1970s. The development of modern educational technology has gone through three stages: integration, networking, and intelligence. Since the 1990s, with the continuous advancement of scientific research, with the continuous advancement of human education, the frequency of multimedia use has become more and more high, which has not only changed the mode of teaching, but also has a profound impact on teaching reform.

Since the beginning of the new century, with the continuous advancement of China's infrastructure, the application of information technology has become more and more extensive. In the auxiliary teaching of computers, schools and departments at all levels have been given more and more attention to modernization. Multimedia classroom teaching has been widely developed in schools at all levels, especially in universities. At the same time, in the process of introducing multimedia teaching mode, many teachers in the multimedia teaching process only use multimedia teaching means as a supplement to the traditional teaching method, but not fundamentally changed from teaching ideas and teaching methods. In the classroom teaching, multimedia gradually replaced the blackboard. Both of teachers and students take multimedia as a relaxing method because instead of writing knowledge in the blackboard, instead of illustrating, teachers just read the PPT; and instead of taking notes, students just take pictures of the PPT in the whole class, thinking that the teaching content can be fully mastered with a glance of the pictures.

So in many multimedia teaching processes, the advantages of multimedia teaching are not reflected. The teaching effect cannot reach the expected ideal state, resulting in the current main problems of multimedia teaching in the following aspects: (1) The relationship between the English teaching system and the textbook. Classroom teaching should get rid of the courseware cramming teaching method, and the multimedia teaching system should be fully utilized to highlight the characteristics of relevant professional courses rather than just copy the content of textbook. Instructors must ensure that the amount of information imparted in courseware is essential and relevant enough while the courseware and the textbook must not be the same. (2) 
The effective combination of traditional teaching and multimedia teaching. Multimedia teaching was not a panacea which can achieve the effect once and for all. Instead of using multimedia teaching to completely supersede traditional teaching, instructors should make full use of the advantages of both traditional teaching and modern multimedia teaching to fully present the various types of teaching content.

In summary, after studying the advantages and disadvantages of multimedia teaching and traditional teaching methods, when instructors design the multimedia teaching system in college English teaching, we need to focus on how to highlight the advantages of multimedia teaching and avoid its disadvantages. In order to enable the designed multimedia teaching system to effectively improve the quality and efficiency of college English teaching and also have practicality, this chapter will further study the characteristics of college multimedia teaching and design a reasonable multimedia teaching system for China's college English teaching based on the practical research.

\section{Theoretical Basis}

\section{Constructivist theory}

The constructivist teaching mode believes that in the teaching process, the students are the center while the teachers are the organizers and the helpers. The students' initiative is fully mobilized by the correlation of context, collaboration, conversation, meaning construction, and finally the meaning of the knowledge is constructed while the learning purpose of students is realized.

The constructivist learning theory lays a theoretical foundation for the application of multimedia in college English reading teaching. The multimedia teaching concept and teaching form are also the teaching concepts advocated by constructivist. Students are the main body, focus on teamwork learning, and learn through situational teaching. The method mobilizes the enthusiasm of the students and makes the students regard learning as a kind of fun and habit. Constructivism advocates that students should learn in the context of problems. The multimedia set is composed of text, graphics, video and audio. It creates realistic teaching links to meet students multiple knowledge demand. By using pictures, texts, videos, etc., the teaching content can be presented realistically in front of the students. It can create good results for students through timely feedback. Constructivism advocates students to actively participate in the construction of knowledge and meaning in an interactive way. In the constructive learning, students are the active constructors of knowledge while teachers play the role of organizers and guides. Teachers mainly stimulate students' interest in learning and find the correlationship between new and old knowledge. Multimedia is not only a means of imparting knowledge, but also a cognitive tool for creating situations and cooperative learning. Under the guidance of the multimedia teaching environment and the construction theory, the teacher-student relationship has undergone great changes. Instead of being the passive recipients, the students have become the main body of teaching, the active constructor of knowledge. Instead of using the traditional method, Multimedia is a cognitive tool for students to complete active meaning construction. 
Vol. 9, No. 2, 2020, E-ISSN: $2226-6348$ @ 2020 HRMARS

Multiple intelligence theory

American educator and psychologist Howard Gardner divides intelligence into: speechlanguage intelligence, music-rhythm intelligence, logic-mathematical intelligence, visual-spatial intelligence, body-sports intelligence, self-knowledge-introspective intelligence, communicationinterpersonal intelligence, natural observer intelligence. Howard Gardner believes that due to the differences in people's intelligent characteristics, each child's multiple intelligence should be developed, and the children with characteristics should be freed from the bundle of traditional education. For cultivating outstanding figures in all fields, the most important factor lies in the development of different potentials of different talents.

The theory of multiple intelligences believes that intelligence must function in a combined form. School education is not only to teach students the teaching content stipulated in the curriculum standards, but educators should also train students to develop a variety of intelligence. In the English reading teaching, multimedia combines the intelligence training of listening, speaking, reading, and writing. For example, by teaching students to learn some popular English songs, apart from stimulating students' interest in learning, it also trained the students' listening and developed the students' musical intelligence and language intelligence. The application of multimedia in college English reading teaching is based on the theory of multiple intelligences theory, which better meet the development needs of learners with different intellectual characteristics and meets the needs of new English classrooms.

\section{Research Methodology Research Object}

In order to comprehensively investigate the application status of multimedia courseware in college English reading teaching, and to be able to conduct real investigation from multiple angles, this survey selected teachers and students from three universities to conduct surveys by purpose sampling. They were from Xi'an Jiaotong University, Xi'an International Studies University and Shaanxi University of Technology. In the three universities, teachers made scientific and reasonable application of multimedia courseware for college English reading teaching. During the survey, it is planned to collect representative courseware for 12 English teachers from three universities; and a questionnaire survey is planned with 100 English teachers and 160 students as samples.

\section{Research Process and Method}

The study lasted for four months (one semester), with a total class time of 130 hours (65 hours for the experimental and 65 hours for the control classes). During the research process, computer and network multimedia were used in the experimental class for English reading teaching, and the traditional teaching method was followed in the control class. Two tests (medium test and posttest) were conducted during the study. Based on the comparison between the two test scores and the students' college entrance examination English scores (pretest), SPSS statistical methods were used for data analysis. A comparative study of multimedia-based English reading teaching methods and traditional English reading teaching methods was conducted. During the experiment and after the experiment, random interviews and questionnaires were 
Vol. 9, No. 2, 2020, E-ISSN: 2226-6348@ 2020 HRMARS

conducted on the students in the experimental class to understand the students' attitude towards the network-assisted English reading teaching, explore the students' ideological trends, and collect good suggestions, so that the experiment was continuously improved.

\section{System Requirements Analysis}

Through the research and extensive investigation of multimedia teaching system in college English reading, the system needs to meet the following requirements:

(1) Teacher teaching. The teacher can control the student to explain the English course to the student through the server system. The student receives the control signal and accesses the teaching resources by the corresponding server under the control of the teacher. The teacher's system has the function of controlling the student's machine, which is convenient for the teacher to check the student's learning progress.

(2) Questions and answers. Students can ask questions to English teachers and teachers give answers in a timely manner. In this mode of teaching, students are no longer passive learners. Through answering questions, teachers can arrange teaching work more reasonably, so that teachers can effectively carry out teaching work.

(3) Easy to manage. The system contains various information, such as pictures, video, audio documents, compressed packages and other resources, which not only enlarges the quantity of teaching resource, but also optimizes the quality of teaching resource. Users can quickly find the corresponding resources when using the system. The classification of various resources must be very clear.

(4) The system has good scalability. It is convenient for programmers to carry out secondary development of the system.

\section{System Implementation}

The related technologies involved in the multimedia teaching system are discussed, such as database technology, B/S software technology system and MVC design pattern technology, which paves the way for the completion of multimedia teaching in the study of college English reading teaching.

\section{Data Technology}

For the multimedia classroom management system, all the information is stored in the database. At present, the database used in the development of software systems has undergone a hierarchical and correlational type, and has developed into a more advanced object-oriented type. Through investigation, the current database system development process will use VF, SQL (Lambert, Holladay \& Drum, 2017), Access and Oracle (Bellec, Lecué \& Tsybakov, 2018). VF (Jovanović, Milenković, \& Pavlović, 2018) and Access database (Shay, Blumenthal, Gadepally, Hamlin, Mitchell \& Cunningham, 2018) store a small amount of data with faster data processing speed. SQL Server data-bases and Oracle databases can be stored, which can facilitate the 
storage and management of various information, but after analyzing the function of the teaching resource, it is found that the Oracle database is too large. If it is adopted, there will be a certain amount of space wastage. Therefore, in the development process of this multimedia classroom management system, we adopted the SQL Server database. This database can ensure that it has a good hierarchical structure in the selection process, and it should be consistent with the information representation model in the software system to ensure the normal storage of data in the system; this database has a standardized data structure that conforms to the design specifications of the database system to satisfy the exchange of information in the database and data in other databases; this database also has high data sharing and data independence to ensure the integrity and security of the application of data information. Finally, the information in the database should have low redundancy, minimize the storage space occupied by the system summary data information, and improve the rate of data retrieval during system operation. SQL Server database is a typical correlational database, which can fully analyze the data information in the database and provide users with a very complete data solution. In addition, it supports Web software architecture and XML (Martens, Neven \& Niewerth, 2017) language, which can reduce user operation practices during the development process. At present, most users use the SQL Server database in the process of software development. The reason is that the database technology has high compatibility, and can easily grasp its development and data storage technology, and can provide users with a reliable data storage platform.

When the SQL server database is designed for software systems, there are several advantages:

(1) The database exhibits high scalability and can conveniently store data information;

(2) The database has decision analysis functions;

(3) The expensive capital required during the purchase and operation process is significantly reduced, which can bring high profits to the enterprise;

(4) It has high compatibility and is convenient for connecting multiple servers.

The SQL server database has high environmental adaptability and can complete the analysis of related data in a short time, which is unachievable by several other database systems. At the same time, it also has high scalability and supports XML language. In order to ensure the security of the information stored in the SQL Server data, it also provides a data encryption function for the user, which basically satisfies the requirements of different users for the confidentiality of the system data, and the addition of the encryption program does not affect the operation of the database itself. In addition, SQL Server can also review all input data information, ensuring the flexibility of parameter configuration in the database.

\section{B/S Software Technology}

$\mathrm{B} / \mathrm{S}$ structure

THE B/S structure is an information system developed under the Internet technology. The structure adopts a three-layer structure, a client, a web server (Juan-Roberto Jiménez, Félix Paulano Godino, José M. Noguera, Juan José \& Jiménez Delgado, 2018) and a data server, and the three are connected through a wide area network. Its structure is shown in Fig. 1. 
Vol. 9, No. 2, 2020, E-ISSN: 2226-6348@ 2020 HRMARS

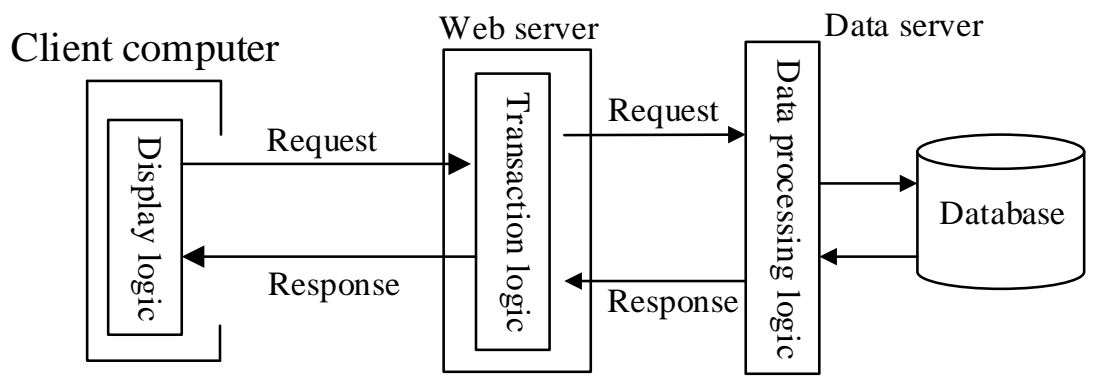

Fig. $1 \mathrm{~B} / \mathrm{S}$ structure

From the Fig. 1, we can see that $\mathrm{B} / \mathrm{S}$ is divided into three layers in structure, namely client, web server and data server. And the three-tier structure is mainly connected according to the Web network. The client mainly completes the human-computer interaction interface, accepts and sends the user's request, and finally displays the result of the data processing. Web server is mainly for the transmission of data information. The data server mainly performs logic functions to process and save data. The data server can receive data operation requests from the web server. The main function is to query the data in the database, modify and store some calculated data to ensure the integrity of the database, and also responsible for the data in the B/S system. The structure is fed back to the web server. The main workflow of B/S is: when the user needs, he will use the browser on the client to make his own request to the web server. After receiving the request from the user, the web server will verify the identity of the user. After the identity, the application required by the user request is first connected to the data server, and then the data processing request is sent to the data server through the application operation. The data server extracts and processes the data, and then the data processing result is performed. Finally, transfer and save. Feedback is still stored in the data server and transferred to the web server, the web server uses the Http protocol, and the protocol will transfer the web page data that the user finds to the client. The client will receive the webpage after receiving the data transmitted by the protocol. The information is displayed on the browser and presented to the user.

\subsubsection{Advantages and disadvantages of $\mathrm{B} / \mathrm{S}$ pattern}

The main advantages of the $B / S$ pattern are:

(1) Simple structure

The $B / S$ structure only needs to be configured with the operating system, network protocol and browser to achieve the functions. This greatly simplifies the client setting. The client application is no longer installed on the client. A universal browser can implement the functionality of all applications. Moreover, the structure is connected by the Internet, and no additional communication connection is required.

(2) Scalability

In the B/S structure, the scope of application can be extended to the entire Internet, which can improve the scalability of the system. Moreover, the system is developed on the basis of Web-based Internet technology. A variety of information can be distributed in the Internet for a wide range of applications. 
Vol. 9, No. 2, 2020, E-ISSN: 2226-6348@ 2020 HRMARS

\section{(3) Simple operation}

The application system of the B/S structure has only one browser. The interface of the browser is universal and easy to operate. No matter what kind of request the user wants to send, the user can operate successfully. The user only needs to know the usage of the browser, and the operation is simple. The application system needs to be specially trained and can be used directly.

Although the $\mathrm{B} / \mathrm{S}$ pattern is now widely used, there are still many problems in the process of use. The shortcomings of the $B / S$ structure are as following:

(1) Low security. The B/S pattern uses an open network, which reduces the security of the B/S.

(2) The response time is long. The B/S pattern is operated through the Web network. During the access process, page refreshing consumes time, reduces the response rate, and in-creases the pressure of database access.

\section{MVC(Model-View-Controller) Pattern}

MVC (Bladin, Axelsson, Broberg, Emmart, Ljung, Bock \& Ynnerman, 2018) organizes code in a way that separates business logic, data from interface display, and aggregates business logic into a single component. It does not require rewriting of business logic while improving and personalizing the interface and user interaction. MVC has been uniquely developed to map traditional input, processing and output functions in the structure of a logical graphical user interface. Fig. 2 shows the main content of the MVC model.

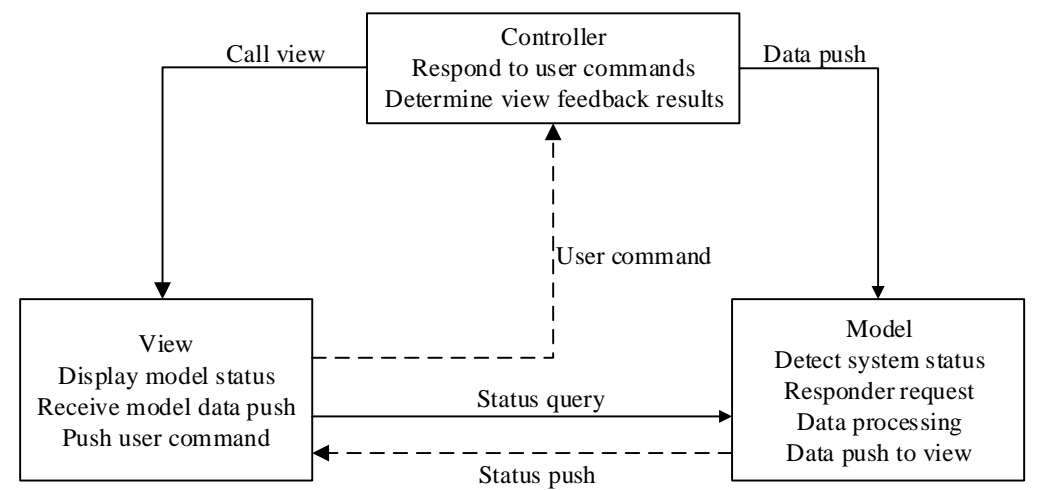

Fig. 2 MVC pattern

\section{The Concrete Realization of Multimedia Teaching System}

After a series of needs analysis, according to the learning process and the functional requirements of the system, a design scheme is proposed for the overall process of the system. All functions of this system need to be logged in before they can be used. When the user logs in, the system determines whether or not to enter the system setting function according to the user's permission, and puts the information of the logged-in user into the session. For security reasons, the system does not allow you to enter the address directly in the address bar for system operation. If the login user directly enters the address, the system will display the error page to remind the user to log in. After the user logs in, the system can perform common learning operations, as shown in Fig. 3 for the system function diagram. 
Vol. 9, No. 2, 2020, E-ISSN: 2226-6348 @ 2020 HRMARS

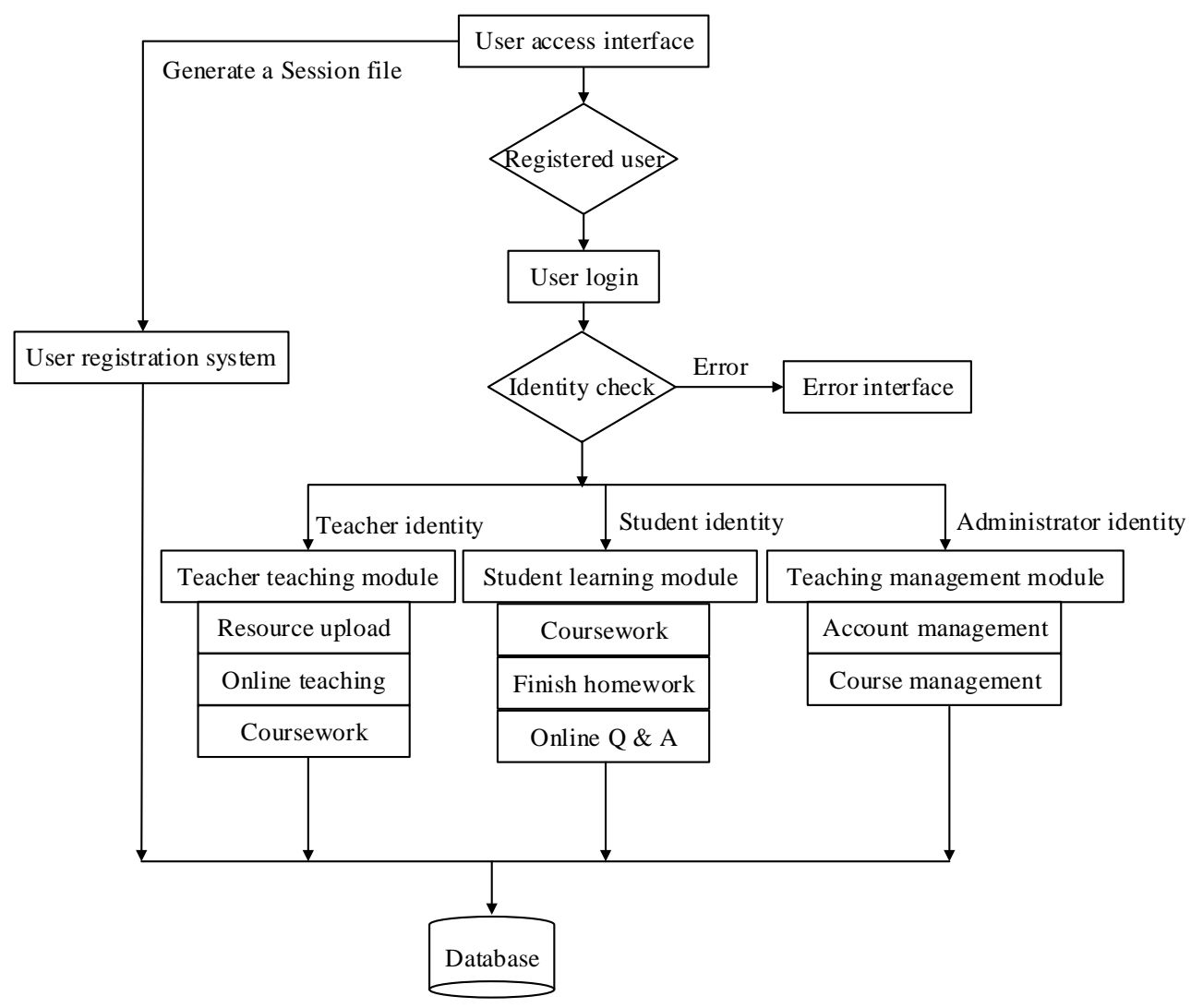

Fig. 3 System function diagram

Login Module Implementation

To avoid duplication of usernames, all user names are assigned by the administrator. At the same time, there is a user name repeat detection button on the right side of the system. If the user name set by the administrator is repeated, the system will give a corresponding prompt. Since the system administrator and the general teacher have different operation rights to the multimedia system, the system also judges the user's operation authority during the login process, and presents different management interfaces according to the user rights. Figure 4 below shows the login interface of the multimedia device management system. 


\section{The Application of Multimedia Teaching in College English Reading Teaching}

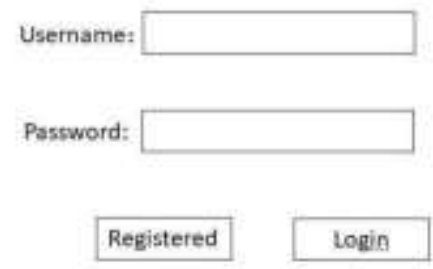

Fig. 4 System login interface

Implementation of the administrator module

After the login is successful, the system directly jumps to the interface shown in Figure 5 below. In this interface, the user can see all the functions that the system can complete in the left function bar. This interface is the interface after the system administrator logs in. It can be seen from the Figure 5 that all function modules can be operated. For the average user, after logging in, only the classroom management module can be seen, and other modules are displayed in gray.

\begin{tabular}{|c|c|}
\hline & Latest notice \\
\hline \multirow[b]{2}{*}{ Equipment management } & Notice about adjustment of class time in multimedia classroom \\
\hline & \\
\hline $\begin{array}{l}\text { Regular inspection } \\
\text { management }\end{array}$ & Notification of equipment maintenance report information \\
\hline User Management & $\begin{array}{l}\text { Notice of the English Academy's Wednesday afternoon } \\
\text { adjustment }\end{array}$ \\
\hline Classroom management & Notification of the upload of teaching resources \\
\hline \multicolumn{2}{|l|}{ Database maintenance } \\
\hline Statistical report & \\
\hline
\end{tabular}

Fig. 5 Administrator interface diagram 


\section{INTERNATIONAL JOURNAL OF ACADEMIC RESEARCH IN PROGRESSIVE EDUCATION AND}

DEVELOPMENT

Vol. 9, No. 2, 2020, E-ISSN: 2226-6348@ 2020 HRMARS

Implementation of teacher teaching module

The teacher users mainly manage the English multimedia course resources. The key contents include the introduction of English teaching content, the planning of teaching progress and the release of multimedia course information. It can also prepare students for after-school materials and questions. The arrangement of English multimedia teaching resources covers English teaching materials of various file types. The system divides the teaching materials into different management directories for organization and classification. Each teaching resource uploads a file of one format. If there are multiple forms of files to upload, the system can operate through batch uploading and upload the English multimedia teaching resources to the resource center. The center then realizes the sharing of multimedia teaching resources. Figure 6 is the interface diagram of teachers uploading multimedia teaching resources in the college English multimedia teaching system.

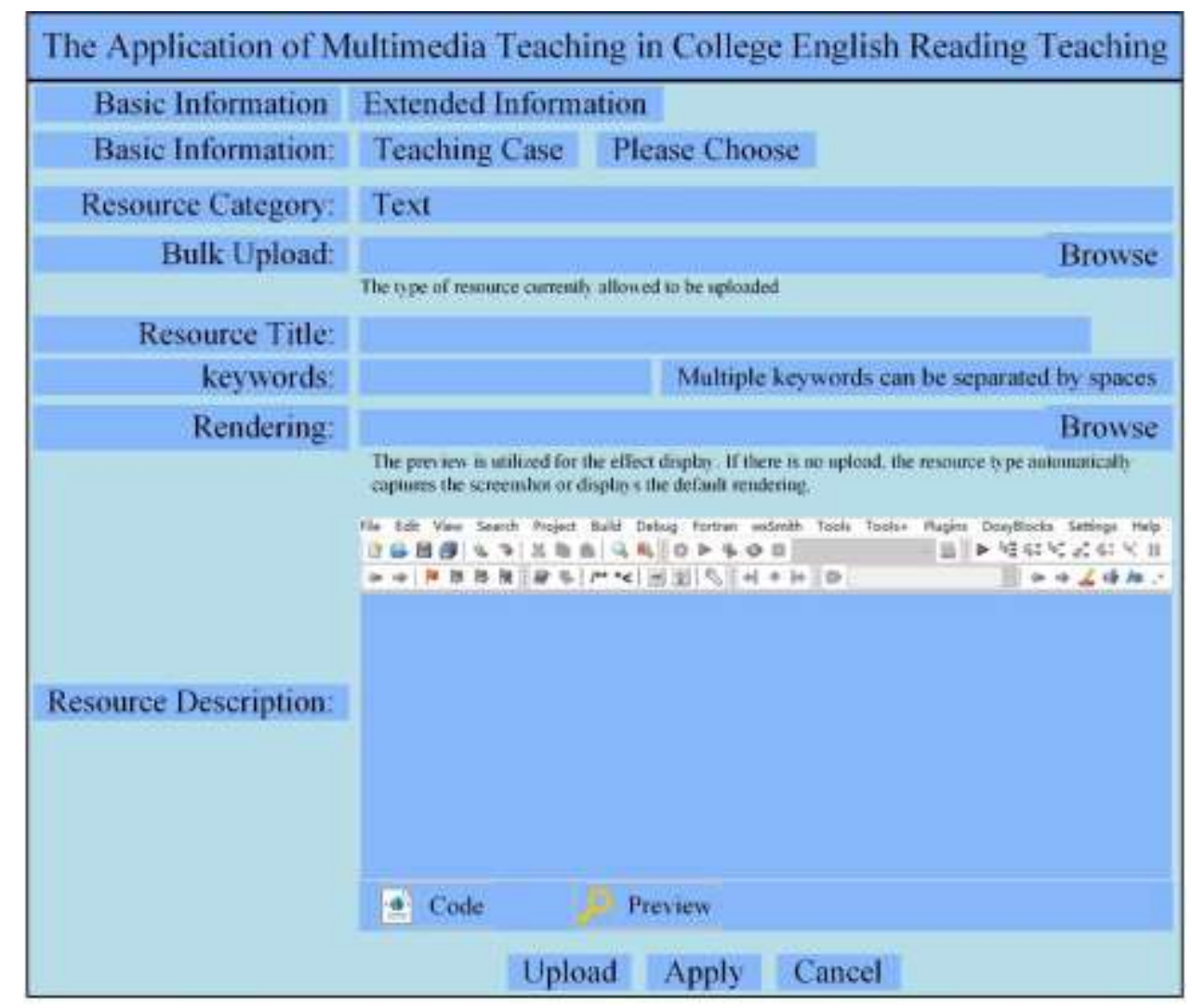

Fig. 6 Teachers upload multimedia teaching resources interface diagram

Student learning module implementation

When students use user login system to learn multimedia English teaching content, students can choose the multimedia English course they need, browse the selected course information and learning materials, participate in the after-school study group to discuss after-school materials, complete homework and classroom tests. 


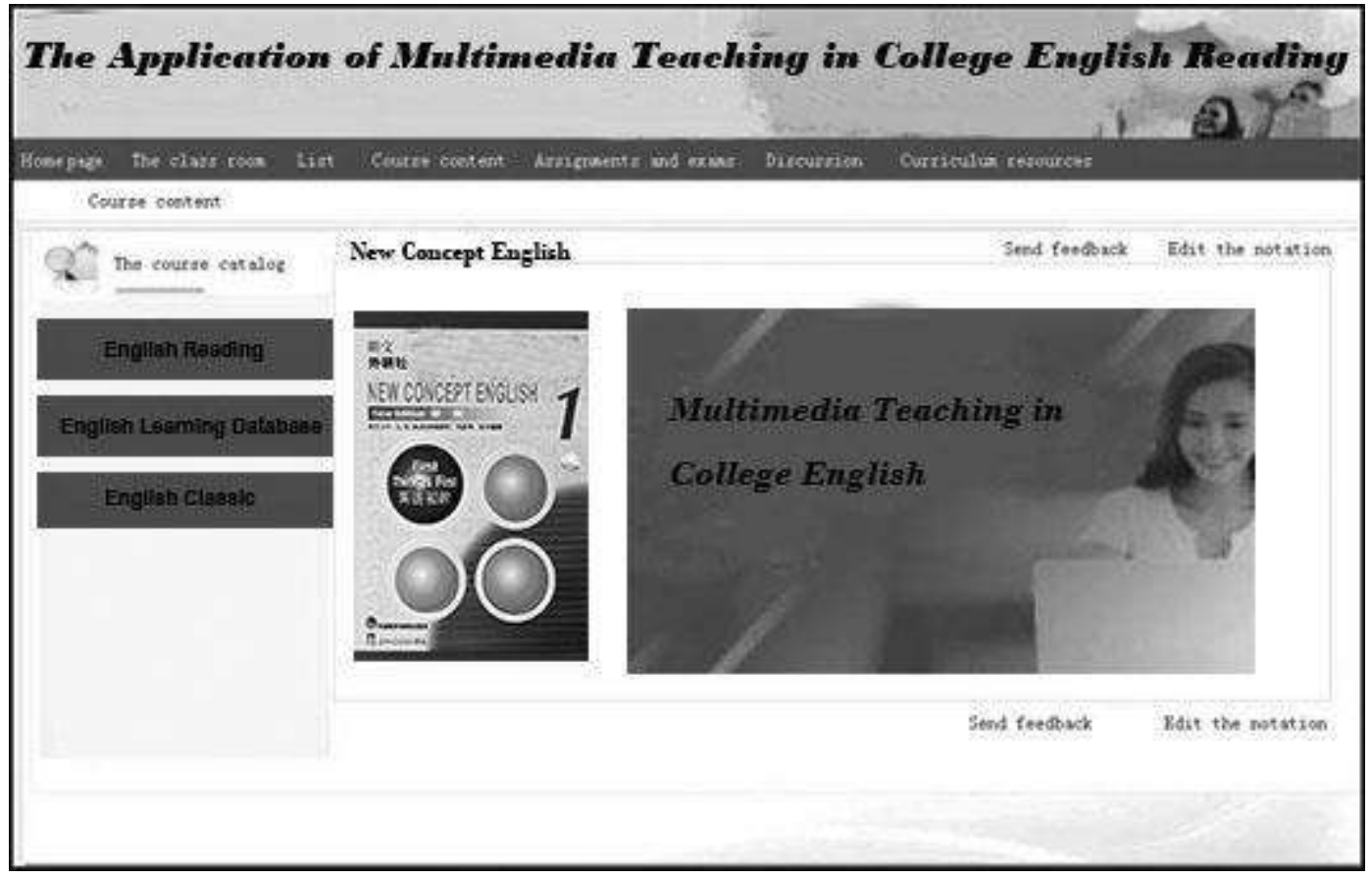

Figure 7 course content interface diagram

As shown in Fig. 7, the implementation of the student's classroom learning content includes a link to the course catalog and the course feedback page. By clicking on one of the courses in the course catalog, students can study English under an autonomous self-learning environment. The course resources cover teaching examples, courseware and other English teaching video data items. Click on the right side of each resource page to display the title and data size of the resource, the student will see the search bar through the top of the page, enter keywords or other resource information, the system will extract the resources required by the student from the system database, and return the results to the students.

\section{Experimental Results and Analysis}

\section{System Operation Effect Test}

Before the experiment was adopted and the system was used, the teachers and students of the class were separately surveyed. The problem was set by the system's effect on teaching and the use of teaching strategies, the configuration of multimedia, teachers Multimedia operation skills, etc. The experiment distributed 100 (teachers) and 160 (students) questionnaires respectively. 
Table 1 Multimedia configuration (teacher questionnaire)

\begin{tabular}{|c|c|c|c|}
\hline Questions & Options & $\begin{array}{c}\text { Number of } \\
\text { people }\end{array}$ & $\begin{array}{l}\text { Percentag } \\
\text { e }\end{array}$ \\
\hline \multirow{3}{*}{$\begin{array}{l}\text { What are the equipments for } \\
\text { assisting } \\
\text { English teaching in your school } \\
\text { (mul- } \\
\text { tiple choices)? }\end{array}$} & Multimedia Class- & & \\
\hline & room & 100 & $100 \%$ \\
\hline & Computer room & 100 & $100 \%$ \\
\hline \multirow{2}{*}{$\begin{array}{l}\text { Is every class in your school } \\
\text { equipped } \\
\text { with multimedia teaching } \\
\text { equipment? }\end{array}$} & $\begin{array}{l}\text { All classrooms are } \\
\text { equipped. }\end{array}$ & 100 & $100 \%$ \\
\hline & $\begin{array}{l}\text { There is only one } \\
\text { public multimedia } \\
\text { classroom. }\end{array}$ & 0 & $0 \%$ \\
\hline \multirow{4}{*}{$\begin{array}{c}\text { Do you think the multimedia equip- } \\
\text { ment can meet the needs of } \\
\text { teaching in }\end{array}$} & Not at all & 3 & $3 \%$ \\
\hline & Make up for it & 5 & $5 \%$ \\
\hline & Basic satisfaction & 35 & $35 \%$ \\
\hline & Full satisfaction & 57 & $57 \%$ \\
\hline
\end{tabular}

Multimedia classrooms are generally equipped with facilities or equipment such as networks, computers, televisions or projectors, and are often used for teaching activities such as open classes for teachers. The language lab room can provide students with the conditions for self-learning. Through the analysis of the survey data in Table 1, it can be known that with the development of society, the government is paying more and more attention to the investment in education. The classes of the three universities in the city surveyed by the author are equipped with multimedia classrooms and computer rooms. The basic multimedia teaching hardware equipment has the conditions for conducting multimedia teaching. The multimedia teaching equipment of each university can basically meet the needs of college English teaching. 
INTERNATIONAL JOURNAL OF ACADEMIC RESEARCH IN PROGRESSIVE EDUCATION AND DEVELOPMENT

Vol. 9, No. 2, 2020, E-ISSN: 2226-6348@ 2020 HRMARS

Table 2 Teacher's Multimedia Operation Skills (Teacher Questionnaire)

\begin{tabular}{|c|c|c|c|}
\hline Questions & Options & $\begin{array}{l}\text { Number } \\
\text { of people }\end{array}$ & $\begin{array}{l}\text { Percentag } \\
\text { e }\end{array}$ \\
\hline \multirow{2}{*}{$\begin{array}{l}\text { Can you search the web page for what } \\
\text { you } \\
\text { need to browse? }\end{array}$} & Can & 100 & $100 \%$ \\
\hline & Cannot & 0 & $0 \%$ \\
\hline \multirow{7}{*}{$\begin{array}{l}\text { Which network resources can you } \\
\text { download }\end{array}$} & Text & 100 & $100 \%$ \\
\hline & Pictures & 98 & $98 \%$ \\
\hline & Music & 88 & $88 \%$ \\
\hline & Video & 85 & $85 \%$ \\
\hline & Animation & 65 & $65 \%$ \\
\hline & Courseware & 95 & $95 \%$ \\
\hline & Software & 45 & $45 \%$ \\
\hline \multirow{4}{*}{ How is your computer operating level? } & Well & 15 & $15 \%$ \\
\hline & Better & 25 & $25 \%$ \\
\hline & General & 55 & $55 \%$ \\
\hline & Poor & 5 & $5 \%$ \\
\hline \multirow{3}{*}{ Do you need to improve your computer? } & Very need & 10 & $10 \%$ \\
\hline & Need & 78 & $78 \%$ \\
\hline & No need & 12 & $12 \%$ \\
\hline \multirow{3}{*}{ What is your computer level? } & First level & 45 & $45 \%$ \\
\hline & Secondary & 55 & $55 \%$ \\
\hline & No level & 0 & $0 \%$ \\
\hline
\end{tabular}

According to the survey in Table 2, all teachers can search in the internet for their own resources, and can download various network resources according to their own needs, but there are few animation and teaching software. This shows that some teachers have not applied the computer skill well to practical teaching. Surveying from the teacher's calculation of the graded certificate, most English teachers passed the National Computer Rank Examination, which met the requirements of the Ministry of Education. In past years, many teachers have received computer-level test certificates because of the teachers' need for promotion and continuing education. However, the computer grade certificate can only indicate that the teacher has the ability to test the computer and cannot indicate its actual application in English teaching. In the investigation, many teachers also indicated that they should strengthen the training of specific 
INTERNATIONAL JOURNAL OF ACADEMIC RESEARCH IN PROGRESSIVE EDUCATION AND

DEVELOPMENT

Vol. 9, No. 2, 2020, E-ISSN: 2226-6348 @ 2020 HRMARS

multimedia operational skills and they must learn to apply the computer technology to their teaching practice.

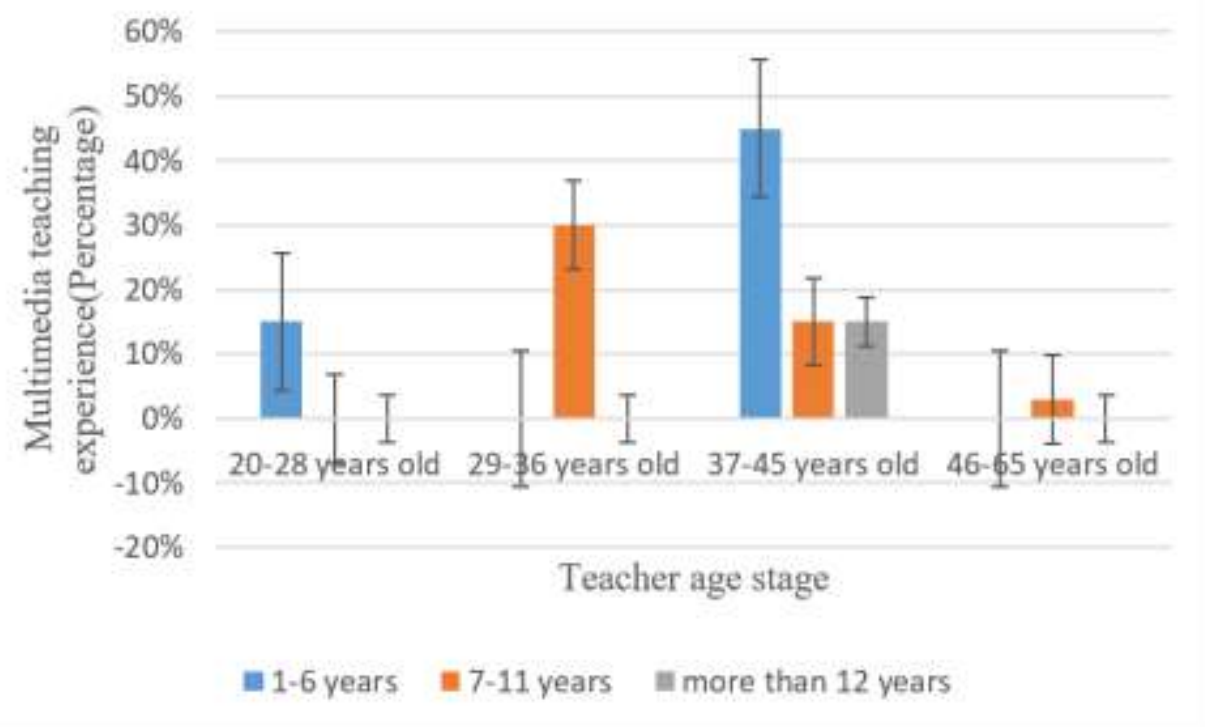

Fig. 8 Multimedia teaching experience and age distribution

As shown in Figure 8, we can see that some older teachers have fewer years of using multimedia courseware. Teachers aged 37-45 have more experience in using multimedia courseware. $15 \%$ of teachers have more than 11 years of experience in using courseware. From the Fig. 6, we can also see that the age of teachers who use multimedia experience in 7-11 years is concentrated on 29-36 years old. Figure 8 shows that some of the older teachers are still not suitable for multimedia courseware-assisted teaching. They usually adopt traditional teaching methods in the classroom. Therefore, older teachers should also update and improve their multimedia technology to adapt to multimedia teaching. 
INTERNATIONAL JOURNAL OF ACADEMIC RESEARCH IN PROGRESSIVE EDUCATION AND DEVELOPMENT

Vol. 9, No. 2, 2020, E-ISSN: 2226-6348 @ 2020 HRMARS

Table 3 classroom teaching effects (student questionnaire)

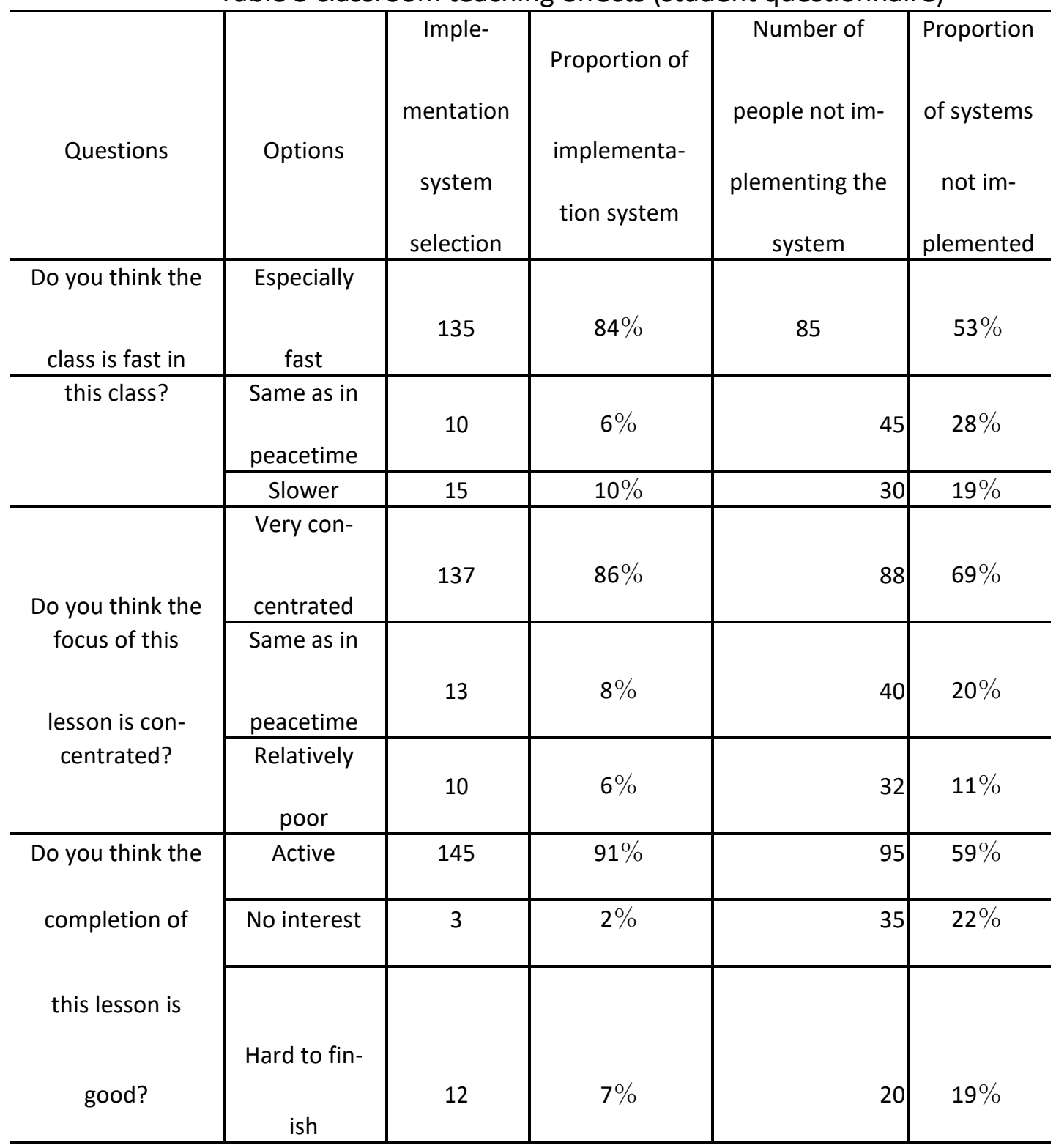

Table 3 shows the classroom effects of the multimedia teaching system. According to the experimental data in Table 1, the students who use this multimedia teaching system have greatly improved their satisfaction with the classroom effect. About $84 \%$ of the students think that the classroom rhythm using multimedia teaching is more compact than that of the former system. The survey indicates that most of students in the multimedia teaching system are very interested in English classes, and the number of students who feel bored in English classes is decreasing, indicating that the classroom effect is better.

In order to find out the application of the teacher's teaching strategy to the students, the following questionnaire questions were set up, and the results of the questionnaire were 
Vol. 9, No. 2, 2020, E-ISSN: 2226-6348@ 2020 HRMARS

analyzed to obtain the application situation of the classroom teaching strategy of this system, as shown in Table 2.

Table 4 Application of classroom teaching strategies (student questionnaire)

\begin{tabular}{|c|c|c|c|}
\hline Questions & Options & $\begin{array}{l}\text { Number of } \\
\text { people }\end{array}$ & $\begin{array}{l}\text { Proportion of the } \\
\text { number of people }\end{array}$ \\
\hline \multirow[b]{2}{*}{ Adopt a group dis- } & Like & 155 & $97 \%$ \\
\hline & No feelings & 2 & $1 \%$ \\
\hline cussion attitude? & Dislike & 3 & $2 \%$ \\
\hline \multirow{3}{*}{$\begin{array}{c}\text { What is the attitude } \\
\text { of the courseware } \\
\text { for } \\
\text { this class? }\end{array}$} & Like & 156 & $98 \%$ \\
\hline & No feelings & 2 & $1 \%$ \\
\hline & Dislike & 2 & $1 \%$ \\
\hline \multirow{3}{*}{ Hope for this kind of } & Continue to keep & 150 & $94 \%$ \\
\hline & Can & 10 & $6 \%$ \\
\hline & Give up & 0 & $0 \%$ \\
\hline
\end{tabular}

From the questionnaire data in Table 4, it can be seen that students like this multimedia teaching system that can combine multiple elements. The simple text teaching can no longer satisfy the students' desire to explore knowledge. In the form of grouping, students have a sense of cooperation and competition, and their self-confidence and satisfaction are greatly improved. $98 \%$ of the students are very satisfied with the teacher's courseware design. The English teaching strategy has achieved effective results because $94 \%$ students hope to continue this kind of class. The students are very satisfied with the teaching strategy of introducing multimedia teaching into the English classroom. The survey results indicate that students hope to continue learning under this kind of teaching strategy and affirm the feasibility of this system in English teaching.

\section{Conclusion}

This paper initiates to design a multimedia teaching system based on B/S network model and MVC design pattern for college English reading teaching. This teaching innovation is based on B/S network mode and MVC design mode, and is composed of Web service layer, client layer and database service layer. The system adopts B/S network and MVC design pattern fusion mode to realize hierarchical control, and different data classification. It refines the functional division of teaching resources, thus greatly improving the capacity of data circulation in the teaching system. The system function design includes four parts: user registration and login, teacher's 
teaching, student's learning and administrator's management. The teacher's teaching module completes the teacher's uploading and online answering function for college English reading materials. The student learning module enables students to obtain classroom learning content and reading resource. Finally, this research discovered that the design of this system has improved the students' interest in learning English and the teaching quality has also been significantly improved.

With the development of information technology, English teaching has been combined with multimedia technology. The constructivist learning theory and the theory of multiple intelligence provide the theoretical basis for multimedia teaching. However, the application of multimedia technology in practical teaching still has some problems. Therefore, this research investigates the application status of multimedia technology in college English reading teaching, aims to solve the problem, and makes multimedia technology play its biggest role in college English reading teaching. At the same time, this paper develops a multimedia teaching systemModel-View-Controller System based on the B/S standard. The Model-View-Controller System is characterized by high reliability, high scalability, high interactivity and high heterogeneity, and it allows learners and teachers to interact without being restricted by time and space, which greatly improves the learning efficiency of learners.

\section{References}

Alessandrini, M., Chakraborty, B., \& Heyde, B. (2018). Realistic vendor-specific synthetic ultrasound data for quality assurance of 2-D speckle tracking echocardiography: Simulation pipeline and open access database. IEEE transactions on ultrasonics, ferroelectrics, and frequency control, 2018, 65(3): 411-422.

Aniche, M., Bavota, G., Treude, C., Gerosa, M. A., \& van Deursen, A. (2018). Code smells for model-view-controller architectures. Empirical Software Engineering, 23(4), 2121-2157.

Antonopoulos, P., Kodavalla, H., Tran, A., Upreti, N., Shah, C., \& Sztajno, M. (2017). Resumable online index rebuild in SQL server. Proceedings of the VLDB Endowment, 10(12), 17421753.

Bellec, P. C., Lecué, G., \& Tsybakov, A. B. (2018). Slope meets lasso: improved oracle bounds and optimality. The Annals of Statistics, 46(6B), 3603-3642.

Bladin, K., Axelsson, E., Broberg, E., Emmart, C., Ljung, P., Bock, A., \& Ynnerman, A. (2018). Globe Browsing: Contextualized Spatio-Temporal Planetary Surface Visualization. IEEE Trans. Vis. Comput. Graph, 24(1): 802-811.

Borland, D., Wang, W., \& Gotz, D. Contextual Visualization. (2018). IEEE Computer Graphics and Applications, 38(6): 17-23.

Chen, Y., Kong, D. (2017). An Investigation on Factors in the Integration of Reciprocal Teaching into Multimedia Teaching. EURASIA Journal of Mathematics, Science \& Technology Education, 13(1): 133-142.

Cornish, A. (2017). Using a native XML database for Encoded Archival Description search and retrieval. Information Technology and Libraries, 23(4): 181-184.

Da-Wei, C., Chao, L., Shun, W., Xunling, W., \& Wenfang, W. (2018). Research and application of multimedia digital platform in the teaching of college physical education course. Journal of Intelligent and Fuzzy Systems, 34(2): 893-901 
INTERNATIONAL JOURNAL OF ACADEMIC RESEARCH IN PROGRESSIVE EDUCATION AND

DEVELOPMENT

Vol. 9, No. 2, 2020, E-ISSN: 2226-6348 @ 2020 HRMARS

Gopalakrishnan, U. P., Rangan, V., Ramkumar, N., \& Hariharan, B. (2019). Parametric evaluation of progressively immersive multimedia representations for teaching environment in elearning. Multimedia Tools Appl. 78(11): 15403-15432.

Hartono, P. (2018). Classification and dimensional reduction using restricted radial basis function networks. Neural Computing and Applications, 30(3): 905-915.

Hornecker, E., \& Honauer, M. (2018). Creating Performance-Oriented Multimedia Projects as Part of an Interdisciplinary Teaching Practice. IEEE Multimedia 25(2): 93-103.

$\mathrm{Hu}$, L. (2017). Design of multimedia teaching platform for Chinese folk art performance based on virtual reality technology. International Journal of Emerging Technologies in Learning (IJET), 12(09): 28-40.

Jiménez, J-R., Godino, F. P., José, M. N., \& Delgado, J. J. J. (2018). Mobile devices in the context of bone fracture reduction: challenges and opportunities. CMBBE: Imaging \& Visualization, 6(4): 371-378.

Jovanović, B., Milenković, S., Pavlović, M. (2018). VT/VF Detection Method Based on ECG Signal Quality Assessment. Journal of Circuits, Systems and Computers, 27(11): 165-169.

Lambert, S. L., Holladay, J., \& Drum, D. M. (2017). International AC: An education case on continuous monitoring SQL server data with ODBC-linked tables in Microsoft access. Journal of Emerging Technologies in Accounting Teaching Notes, 13(2), 5-30.

Larralde, M., Lawson, T. N., \& Weber R J M,. (2017). mzML2ISA \& nmrML2ISA: generating enriched ISA-Tab metadata files from metabolomics XML data. Bioinformatics, 33(16): 2598-2600.

Leite, V. M., Palma, J. G., \& de Oliveira, F. H. (2017). Definition of a Computing Independent Model and Rules for Transformation Focused on the Model-View-Controller Architecture. World Academy of Science, Engineering and Technology, International Journal of Computer, Electrical, Automation, Control and Information Engineering, 11(2), 244-251.

Li, H., Xu, Z., Li, T., Sun, G., Kim-Kwang., \& Choo, R. (2017). An optimized approach for massive web page classification using entity similarity based on semantic network. Future Generation Comp. Syst, 76: 510-518.

Martens, W., Neven, F., \& Niewerth, M. (2017). Bonxai: Combining the simplicity of DTD with the expressiveness of XML schema. ACM Transactions on Database Systems (TODS), 42(3): 15.

Qazi, N., McElholm, M., \& Maguire, L. (2018). A Model-View-Controller (MVC) architecture for contextual visualisation of task-based multi-dimensional energy KPIs in a manufacturing process. International Journal of Ambient Energy, 39(4): 406-413.

Shay, R., Blumenthal, U., Gadepally, V., Hamlin, A., Mitchell, J. D., \& Cunningham, R. K. (2018). Don't Even Ask: Database Access Control through Query Control. SIGMOD Record, 47(3), 17. 


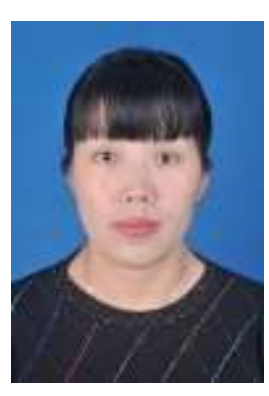

Juan Lu was born in Hanzhong, Shaanxi, China, in 1981. She received the bachelor's degree and master's degree from Xi'an International Studies University, P.R. China. After graduation, she teaches in Shaanxi University of Technology, and now she is studying for her PhD in Universiti Teknologi Malaysia. Her research interest includes Education Technology \& computer science, Linguistics, and translation.

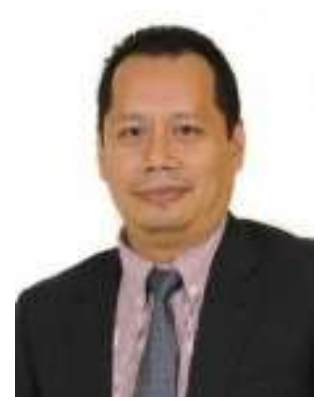

Noraffandy Yahaya is an Associate Professor at school of Education, Universiti Teknologi Malaysia since 2013. He is Head of Department at Department of Educational Science, Mathematics and Creative Multi-media from 2009 to present. Noraffandy has research background in Online Learning and ICT in Education. He has conducted studies on students' interaction in online learning environment, Learning Analytics and Massive Open Online Course (MOOC). He has published more than 50 papers in the research area of Online Learning, ICT in Education and the use of technology in teaching and learning. He has been a supervisor to more than 25 completed master degree students

and 10 completed PhD students. Currently, he has 11 PhD students under his supervision. He has also been appointed as external examiner for universities in Malaysia and Australia for doctoral theses and has been an assessor for Master dissertation for university in New Zealand. 